\title{
A PRODUÇÃO CIENTÍFICA SOBRE RISCOS OCUPACIONAIS A QUE ESTÃOO EXPOSTOS OS TRABALHADORES DE ENFERMAGEM
}

\author{
The Scientific Production about Occupational Risks to \\ Which the Nursing Workers are Exposed \\ La Producción Científica sobre Riesgos Ocupacionales \\ a que están Expuestos los Trabajadores de Enfermería
}

Magda Ribeiro de Castro ${ }^{1}$

Sheila Nascimento Pereira de Farias ${ }^{2}$

\begin{abstract}
Resumo
Estudo realizado no Curso de Mestrado na Escola de Enfermagem Anna Nery, inserido no Núcleo de Pesquisa em Enfermagem e Saúde do Trabalhador da Universidade Federal do Rio de Janeiro. Objeto: a produção científica sobre riscos ocupacionais a que estão expostos os trabalhadores de enfermagem. Objetivos: levantar a produção científica dos estudos stricto sensu acerca dos riscos ocupacionais nos trabalhadores de enfermagem; identificar a abordagem (objetiva ou subjetiva) acerca desses riscos e analisar os riscos retratados. Estudo bibliográfico e quantitativo dos 42 resumos publicados no Centro de Estudos e Pesquisas em Enfermagem entre 1979 e 2004. Riscos mais expressivos: biológicos, seguidos dos químicos, dos psicossociais e, em menor escala, dos físicos, de acidentes e ergonômicos. Percebeu-se reduzida ênfase dispensada à subjetividade do trabalhador de enfermagem associada à temática estudada, sugerindo lacuna nesta área de conhecimento. Faz-se necessária a reflexão desses riscos na enfermagem, atentando para sua identificação, detecção e controle.
\end{abstract}

Palavras-chave: Riscos Ocupacionais. Enfermagem. Saúde do Trabalhador.

\begin{abstract}
Study carried out on the Master of the Nursing College Anna Nery, inserted on the Research on Nursing and Worker Health Center of the Universidade Federal do Rio de Janeiro. Object: the scientific production about occupational risks to which the nursing workers are exposed Goals: surveying the scientific production of stricto sensu studies about the occupational risks among the nursing workers, identifying the approach (objective or subjective) about these risks and analyze the risks presented. Bibliographical and quantitative study of the 42 abstracts published on the Unit of Nursing Studies and Researches from 1979 until 2004. More expressive risks: biological ones, followed by the chemical, psycho-social ones and, on lesser scale, physical, from accidents and ergonomic ones. A reduced emphasis is given to the subjectivity of the nursing worker associated to the studied subject, which suggests a gap on this domain of knowledge. It is necessary to reflect about these risks on nursing, paying attention to their identification, detection and control.
\end{abstract}

Keywords:

Occupational Risks, Nursing, Worker Health.

\section{Resumen}

Estudio realizado en el Curso de Maestría de la Escuela de Enfermería Anna Nery, inserto en el Núcleo de Investigación en Enfermería y Salud del Trabajador de la Universidad Federal de Río de Janeiro. Objeto: la producción científica sobre riesgos ocupacionales a que están expuestos los trabajadores de enfermería. Objetivos: hacer un búsqueda de la producción científica de los estudios stricto sensu acerca de los riesgos ocupacionales en los trabajadores de enfermería; identificar el abordaje (objetivo o subjetivo) acerca de los riesgos y analizar los riesgos retratados. Estudio bibliográfico y cuantitativo de 42 resúmenes publicados en el Centro de Estudios e Investigación en Enfermería entre 1979 a 2004. Riesgos mas expresivos: biológicos, seguido de químicos, psicosociales y en menor escala, los físicos, accidentes y riesgos ergonómicos. Se percibió reducido énfasis dispensado a la subjetividad del trabajador de enfermería asociada a la temática estudiada, sugiriendo lagunas en esta área de conocimiento. Se hace necesaria la reflexión de estos riesgos en la enfermería, prestando atención para su identificación, detección y control.

Palabras clave:

Riesgos Ocupacionales. Enfermería. Salud del Trabajador. 


\section{INTRODUÇÃO}

No que se refere ao contexto laboral, Athayde ${ }^{1: 69}$ ressalta que "a produção capitalista demanda trabalhadores livres/ expropriados, prontos para venderem sua força de trabalho ao capital", o que gera progressivamente e, ao longo do tempo, consumos crescentes na sociedade. Esse consumo muitas vezes motiva o trabalhador a trabalhar incessantemente com um único objetivo de consumir, sem limites. Dessa forma, o indivíduo "vive para trabalhar" e "trabalha para consumir".

Assim, ao analisar o contexto atual, verifica-se que tal prática é muito comum entre os trabalhadores da saúde, em especial, da enfermagem, que ganham a vida correndo de um posto de trabalho para outro sem, muitas vezes, questionar os riscos a que estão expostos no ambiente laboral, a qualidade do cuidado que oferece ao cliente, sua própria qualidade de vida e, muito menos, o seu autocuidado - o cuidar de si.

Desenha-se assim, na era da globalização, o quadro da modernização tecnológica, da privatização e terceirização dos postos de trabalho, da concorrência e competitividade entre os homens e a precarização de emprego, de condições de trabalho, salários, enfim, condições necessárias ao sustento, bem-estar e saúde do trabalhador.

Dentro deste panorama, no que se refere aos riscos ocupacionais, ressalta-se que os mesmos se originam de atividades laborais insalubres e perigosas, podendo provocar efeitos adversos à saúde do trabalhador exposto, o que corrobora Mauro 2:342 ao referir que "os estudos sobre os riscos ocupacionais apontam que, quando eles não são submetidos a controle, levam ao aparecimento de acidentes e doenças profissionais e do trabalho".

Assim sendo, verifica-se que o estudo desses riscos tem sido tema de discussão na academia; no entanto, no estudo ora apresentado, o interesse em conhecer as pesquisas envolvendo tal temática deve-se ao fato de sua importância para enfermagem e seus trabalhadores, dada a ocorrência de um índice elevado de acidentes de trabalho nesta categoria profissional.

Esse conhecimento aos estudos já realizados teve como finalidade evidenciar como os riscos ocupacionais foram abordados e se os mesmos referenciaram aspectos subjetivos do trabalhador que envolvessem o desfecho do acidente de trabalho.

Para efeitos desse estudo, consideram-se aspectos subjetivos aqueles relativos ao sujeito como ser único, individual, de caráter pessoal e intransferível. Essa concepção encontra apoio em $\mathrm{Abbagnano}^{3}$ ao referir que o subjetivo tem o sentido de ser válido para uma só pessoa e não para as outras.

Diante do exposto, destaca-se como objeto desta pesquisa a produção científica sobre riscos ocupacionais a que estão expostos os trabalhadores de enfermagem.

\section{Objetivos}

- Levantar a produção cientíica dos estudos stricto sensuacerca dos riscos ocupacionais nos trabalhadores de enfermagem;

- Identificar nos estudos stricto sensu a forma de abordagem (objetiva ou subjetiva) acerca dos riscos ocupacionais para os trabalhadores de enfermagem;

- Analisar os riscos ocupacionais retratados nesses estudos.
Nesta perspectiva, adotou-se no estudo em tela a forma de abordagem subjetiva como aquela pautada em Laurell e Noriega ${ }^{4}$ referente à experiência subjetiva do trabalho como fonte de tensão e danos à saúde, que abrangem as características consideradas estressantes do ambiente laboral; a sensação de mal-estar ao se dirigir para o trabalho; a fadiga física e mental ao terminar a jornada; 0 absenteísmo e a incapacidade por doença relacionada com a tensão ou fadiga. Não obstante, a abordagem objetiva é aquela passivel de quantificação através de aparelhos, escalas e instrumentos, mensuração e observação. Ou seja, o objetivo "é válido para todos", e, em última análise, é comum a diversos seres e "poderia ser comum a todos" 3:692, o que corrobora Laurell e Noriega ${ }^{4}$ ao afirmarem que a pretensão em constituir um método objetivo de estudo visa estabelecer um referencial comum aceitável para as partes interessadas nos problemas, assim, aplica-se "ferramentas e regras aceitáveis para todos" \$:67.

\section{J ustificativa}

Ao elucidar os mecanismos que ocasionam acidentes de trabalho, faz-se necessário conhecer as pesquisas que tratam de riscos ocupacionais aos quais os trabalhadores de enfermagem estão expostos, identificando os aspectos mais significativos para esta equipe profissional. Evidenciam-se, assim, as lacunas de conhecimento existentes, favorecendo 0 desenvolvimento de estudos que preencham as mesmas. Neste sentido, se poderão desenvolver mecanismos de controle e prevenção objetivando a redução desses riscos, a promoção da saúde dos trabalhadores e conseqüente redução de acidentes.

Acredita-se que este pensamento esteja em conformidade com a Constituição da República Federativa do Brasil, inciso XXII, artigo $7^{\circ}$, que faz referência à redução dos riscos inerentes ao trabalho, por meio de normas de saúde, higiene e segurança ${ }^{5}$.

Portanto, ao estudar os riscos ocupacionais, destaca-se a classificação de Moraes ${ }^{6}$, que os divide em cinco grupos, conforme sua natureza, a saber: riscos físicos; químicos; biológicos; ergonômicos e de acidentes.

De acordo com a classificação referida, percebe-se que os trabalhadores de enfermagem estão expostos a inúmeros riscos que podem causar agravos à sua saúde, acidentes de trabalho e/ou doenças, principalmente durante a assistência ao cliente, e que essa exposição pode trazer conseqüências para a saúde do trabalhador em vários aspectos: físico, psíquico, emocional e social. Verifica-se, então, que os riscos são constantes e muitas vezes concomitantes no ambiente laboral expondo toda a equipe de saúde.

$M$ Mauro $^{2}$ em seu estudo classifica os fatores de risco para a saúde e segurança dos trabalhadores, presentes ou relacionados ao trabalho, em cinco grandes grupos: físicos, químicos, biológicos, ergonômicos e psicossociais (que decorrem da organização e gestão do trabalho), e, por último, os riscos de acidentes. Nesse sentido, percebe-se a existência de preocupação com o aspecto psicossocial do trabalhador, sendo este permeado de subjetividade; portanto, um aspecto importante na identificação dos riscos ocupacionais, pois através dele inúmeros problemas de ordem subjetiva decorrem em função do trabalho desenvolvido afetando a saúde do trabalhador. 


\section{METODOLOGIA}

Realizou-se um estudo bibliográfico através da abordagem sistemática que, segundo Haber ${ }^{7}$, se refere a uma estratégia de amostragem que envolve a seleção de cada caso extraído de uma lista de população em dado intervalo. Nesse caso, a população constou de resumos publicados na Ficha Catalográfica do Centro de Estudos e Pesquisas em Enfermagem (CEPEN), apresentando um lapso temporal de 25 anos, compreendendo o período de 1979 a 2004, o que está em consonância com a autora mencionada, uma vez que a mesma afirma que quando essa abordagem é usada, a população tem de ser estreitamente definida. Assim, realizouse o estudo em tela por meio de resumos de estudos científicos conclusivos de pós-graduação ao nível stricto sensu na área da Enfermagem acerca dos riscos ocupacionais.

Dessa forma, esse estudo foi desenvolvido concentrando resumos publicados no catálogo CEPEN elaborado pela Associação Brasileira de Enfermagem (ABEN), que tem como seus compromissos a promoção, divulgação e socialização do conhecimento em Enfermagem, editando desde 1979 o catálogo "Informações sobre Pesquisas e Pesquisadores em Enfermagem" ${ }^{8}$ que "congrega as teses e dissertações produzidas por Enfermeiros vinculados aos Programas/Cursos de Pós-Graduação, especialmente em Enfermagem"8.

0 acesso ao catálogo deu-se através da consulta ao CD $\mathrm{ROM}^{8}$, sendo possível resgatar todos os volumes editados no período de 1979 a 2000, correspondendo aos volumes publicados de I a XVIII, e por meio da consulta ao site da ABEN $^{9}$, permitindo 0 acesso aos volumes XIX a XXIII, correspondendo, respectivamente, aos anos de 2001 a 2004.

A pesquisa no catálogo em questão foi realizada através do item assunto, que desencadeou a escolha pelo termo riscos ocupacionais. Desse modo, realizou-se a leitura no CD ROM e no site de todos os resumos resultantes da investigação pelo termo escolhido.

A partir deste levantamento, foi possível identificar os estudos existentes no catálogo pesquisado no recorte temporal de 1979 a 2004, perfazendo um total de 42 resumos com a temática riscos ocupacionais. Utilizou-se abordagem quantitativa, e os dados foram organizados, quantificados e dispostos em quadro, sendo destacado o título do estudo, ano, tipo de estudo (dissertação ou tese) e universidade (Quadro I - Resumos identificados, em anexo).

\section{ANÁLISE E DISCUSSÃO DOS DADOS}

Em relação à idéia central dos resumos, verificou-se que quatro estudos $(9,5 \%)$ destacaram os acidentes de trabalho, abordando os acidentes ocorridos em coletores de lixo; acidentes com sangue e outros fluidos corpóreos; acidentes com exposição aos líquidos corporais humanos e acidentes com trabalhadores de um hospital escola.

A mesma proporção de estudos (9,5\%) foi encontrada nos que abordam os riscos ocupacionais, versando sobre os riscos em hospitais; riscos em Centro Municipal de Saúde; a educação revelando os riscos e situações de risco para transmissão de patógenos veiculados pelo sangue.

Destacam-se três estudos $(7,1 \%)$ que abordaram os dois assuntos em conjunto, enfocando a prevenção da situação de risco e de acidente de trabalho; os riscos ocupacionais e acidentes do trabalho e morbidade entre motoristas de uma central de ambulância; e riscos ocupacionais e acidentes do trabalho em Unidade de Terapia Intensiva.

Desse modo, observa-se a ênfase dada nas pesquisas aos acidentes de trabalho e riscos ocupacionais, totalizando, no estudo em tela, o correspondente a $26,1 \%$ dos resumos identificados.

Moraes $^{6}$ assevera que acidente de trabalho é o que ocorre pelo exercício das atividades laborais, a serviço da empresa, provocando lesão corporal ou perturbação funcional que cause a morte, a perda ou redução, temporária ou permanente, da capacidade para o trabalho. Entretanto, nos resumos estudados, os acidentes de trabalho enfocaram aqueles ocorridos com sangue e/ou exposição a outros fluidos corpóreos, o que demonstra a freqüente exposição dos trabalhadores de enfermagem aos riscos biológicos e a constante preocupação com a transmissão de patógenos veiculados pelo sangue e líquidos corporais.

Mauro ${ }^{2: 340}$ confirma esse achado em seu estudo, mencionando que "embora se saiba que acidentes com material biológico não acontecem somente com enfermeiros ou técnicos de enfermagem, há estudos que indicam a hegemonia dessa categoria nos incidentes, especialmente em acidentes com material perfurocortantes". Dessa forma, ressalta-se que muitos acidentes envolvendo material biológico se devem ao uso de materiais perfurocortantes, instrumentos que fazem parte do processo de trabalho da enfermagem.

Ainda nessa vertente, Spíndola ${ }^{10}$ afirma que os acidentes de trabalho ocorrem em todas as categorias profissionais conforme a natureza do trabalho executado. Todavia, as atividades realizadas pelos profissionais de saúde e a qualidade do material que manipulam despertam a preocupação dos estudiosos pela exposição destes trabalhadores aos acidentes de trabalho, especialmente aqueles com material perfurocortante, em decorrência dos riscos à saúde que podem acarretar.

Quatro estudos $(9,5 \%)$ versam sobre a exposição ocupacional envolvendo a hipersensibilidade ao látex; o vírus da AIDS e hepatite B; as substâncias químicas e os trabalhadores de enfermagem; e adesão de trabalhadores de enfermagem ao tratamento com antiretrovirais pós-exposição ocupacional.

Nota-se, mais uma vez, o destaque aos riscos biológicos nos estudos investigados, com ênfase especial dispensada aos vírus HIV e HBV. Para Moraes ${ }^{6}$, os riscos biológicos envolvem vírus, bactérias, fungos, parasitas e bacilos, idéia pertinente com 0 pensamento de Mauro ${ }^{2}$ ao mencionar que os riscos biológicos envolvem os microorganismos geralmente associados ao trabalho em hospitais. Assim, pode-se inferir que a evidência dada a esse risco deve-se em função das atividades desempenhadas e características peculiares de trabalho da equipe de enfermagem.

Observou-se que quatro estudos $(9,5 \%)$ abordam os quimioterápicos como uma questão de saúde do trabalhador; riscos para os trabalhadores que preparam e administram essas 
substâncias; perigos na manipulação; e morbidade da equipe de enfermagem que trabalha com quimioterápicos.

Nesses estudos, os riscos químicos foram apontados e representados principalmente pelos quimioterápicos quanto ao seu preparo, administração, manipulação e riscos à saúde do trabalhador exposto. Vale ressaltar, que o trabalhador de enfermagem também se encontra freqüentemente exposto a esse grupo de risco, muito comum nos processos de trabalho que envolvem os agentes e substâncias químicas em geral.

A biossegurança esteve presente em quatro estudos $(9,5 \%)$ sobre o cotidiano de enfermeiros e auxiliares de enfermagem; o preparo, administração e descarte de agentes antineoplásicos injetáveis; a cobertura vacinal entre enfermeiros; e o compromisso pelo cuidado seguro.

No que tange à biossegurança, vale destacar a amplitude do seu conceito assim como de seu campo de atuação, permeando desde ações voltadas para prevenção, minimização ou eliminação de riscos até as atividades de pesquisa, produção, ensino, desenvolvimento tecnológico e prestação de serviços, além da preocupação com a saúde do homem e com o meio ambiente ${ }^{11}$.

Quatro estudos $(9,5 \%)$ identificaram os danos causados à saúde do trabalhador decorrentes de sua atividade laboral, enfatizando: os distúrbios osteomusculares e a enfermagem hospitalar; o estresse nos trabalhadores de enfermagem; danos conseqüentes da prática hospitalar (sendo a hepatite a doença que mais acometeu o pessoal da enfermagem); e adoecimento dos trabalhadores de enfermagem (incluindo os distúrbios do sistema osteomuscular, seguidos dos transtornos mentais e comportamentais, dentre outros).

Observa-se através desses estudos a causa de danos e/ou adoecimento dos trabalhadores de enfermagem decorrentes da atividade laboral, estando os distúrbios osteomusculares presentes em mais de um estudo, sendo esse um agravo que tem acometido em grande escala a equipe de enfermagem, em especial, sob a forma de lombalgias.

A aquisição de hepatite decorrente do trabalho também esteve presente nos estudos; dessa forma, os profissionais de enfermagem devem estar atentos quanto à exposição ao material biológico devido ao risco de contaminação pelo HIV, HBV e HCV. Segundo Fagundes ${ }^{12}$, tais riscos são de até $0,3 \%$ para o HIV, $10 \%$ para o HCV e $30 \%$ para HBV, e acrescenta que, embora a probabilidade de infecção pelo HIV seja pequena, as conseqüências para a vida do profissional são catastróficas. Por outro lado, afirma que a probabilidade de infecção pelo HBV é a mais alta e, ao longo prazo, também pode ser fatal.

Outros danos causados ao trabalhador, como estresse e transtornos mentais e comportamentais decorrentes do trabalho, também estiveram explícitos nos estudos investigados, o que pode permitir uma associação com os aspectos subjetivos seguindo a linha de pensamento de Mauro², que em seu estudo traz a noção de subjetivo, relativo à variação individual, a qual reflete a história pessoal de cada um. De acordo com as idéias dessa autora, a subjetividade encontra aderência nos riscos ocupacionais classificados como psicossociais.

De acordo com as idéias de Laurell e Noriega ${ }^{4}$, os problemas de saúde originados pelo trabalho, assim como tensão e fadiga, relacionam-se com a experiência subjetiva do trabalhador. Logo, esses estudos caracterizam-se dotados de abordagem subjetiva, uma vez que, segundo o Quadro I (resumo 23), concluiu-se que as condições de trabalho dos auxiliares foram consideradas inadequadas, havendo inobservância dos princípios ergonômicos e da proteção à saúde, resultando na ocorrência de problemas osteomusculares; enquanto o resumo 24 apontou osfatores existentes no local de trabalho que podem gerar estresse, revelando, nos resultados, que os profissionais de enfermagem conhecem os principais fatores de estresse e os relacionam a problemas de trabalho, seguidos de problemas do ambiente e pessoais.

Ainda nesta vertente, o resumo 39 investigou os reflexos da prática hospitalar causadores de danos à saúde dos trabalhadores de enfermagem, e o 41 constatou que a força de trabalho da enfermagem está sendo consumida por danos que afetam o corpo e a mente em decorrência de enfermidades causadas por violência oculta no trabalho, conhecidas também como doenças da modernidade, tais como LER/DORT, depressão, angústia, estresse, dentre outras, além de outras formas de adoecimento pelo trabalho devido à exposição ocupacional aos riscos biológicos, físicos, químicos, ergonômicos e psicossociais.

Vale destacar que, nesse item (danos causados à saúde do trabalhador), o estresse e os transtornos mentais configuram-se como agravos caracterizados por danos fisiológico e/ou psíquico, sendo este último nem sempre aparente, porém totalmente subjetivo.

Outros enfoques estiveram associados aos riscos ocupacionais identificados nos estudos stricto sensu em menor proporção que os mencionados anteriormente. São eles: a importância do conhecimento e aplicação das precauções universais; o significado do risco de infecção pelo HIV e riscos biológicos. Esses enfoques surgiram em dois estudos, correspondendo, respectivamente, a $4,8 \%$ dos resumos identificados. Percebe-se que esses achados estão em conexão com o que foi discutido ao longo desta seção, uma vez que é possível associar as precauções universais às normas de biossegurança, visando à minimização da exposição aos riscos ocupacionais, em especial os biológicos, estando mais uma vez representados pelo vírus da Síndrome da Imunodeficiência Adquirida.

Entretanto, nota-se que os riscos físicos, de acidentes e ergonômicos foram pouco discutidos nos estudos investigados, estando presentes em apenas um estudo, o que corresponde, respectivamente, a 2,4\% dos resumos identificados. Nessa mesma proporção, encontram-se pesquisas abordando o uso de equipamento de proteção individual; tuberculose em pacientes internados e equipe de enfermagem; exercício no banho de aspersão; riscos do mercúrio no amálgama dental; prostituição como ocupação de risco; e riscos numa empresa eletricitária.

Dessa forma, fica claro que todas as ocupações estão expostas a riscos e agravos que dependerão de suas atividades profissionais, não sendo, portanto, mérito da equipe de saúde nem tampouco da equipe de enfermagem.

Entretanto, através desses estudos, foi possível verificar que a equipe de enfermagem está exposta aos diversos riscos ocupacionais, estando bem evidente os riscos biológicos, seguidos dos químicos, dos psicossociais e, em menor escala, dos riscos físicos, de acidentes e ergonômicos. 
Ressalta-se que apenas quatro estudos (9,52\%) abordaram fatores que sugerem associação com a subjetividade do trabalhador, tais como o estresse e a ocorrência de transtornos mentais e comportamentais neste indivíduo, apresentando o tipo de abordagem subjetiva apoiada em Laurell e Noriega ${ }^{4}$ contra $38(90,47 \%)$ com abordagem objetiva. Além disso, cinco estudos não tiveram como foco de atenção os trabalhadores de enfermagem, e sim outras categorias profissionais e outros espaços laborais, como, por exemplo, o trabalho numa empresa eletricitária, com coletores de lixo, motoristas de ambulâncias e outros.

Através desta análise, foi possível conhecer os estudos abordando os riscos ocupacionais no catálogo CEPEN e perceber a reduzida ênfase dispensada à subjetividade do trabalhador de enfermagem associada a essa temática, sugerindo uma lacuna nesta área de conhecimento.

Dessa forma, acredita-se na relevância em estudar os aspectos subjetivos do trabalhador, encontrando respaldo em Starling ${ }^{13: 63}$, que concluiu seu estudo afirmando que "um dos grandes problemas é que a dimensão subjetiva não é incorporada na compreensão dos agravos à saúde no ambiente de trabalho".

\section{CONSIDERAÇÕES FINAIS}

0 estudo contribuiu para ampliar o conhecimento acerca da temática risco ocupacional envolvendo a equipe de enfermagem e possibilitou vislumbrar e levantar a produção científica sobre esse tema desenvolvida pelo Catálogo CEPEN entre os anos de 1988, registro dos primeiros trabalhos acerca

\section{Referências}

1. Athayde M. Produção de subjetividade frente à produção bloqueada: os "sem" e a cena do corte. In: Silva FJF, Jardim SR. A danação do trabalho: organização do trabalho e sofrimento psíquico. Rio de Janeiro (RJ): Te Corá; 1997.

2. Mauro MYC, Muzi CD, Guimarães RM, Mauro CCC. Riscos ocupacionais em saúde. Rev Enferm UERJ 2004; 12: 338-45.

3. Abbagnano N. Dicionário de Filosofia. São Paulo (SP): Mestre Jou; 1998

4. Laurell AC, Noriega M. Processo de produção e saúde: trabalho e desgaste operário. São Paulo (SP): Hucitec; 1989.

5 Constituição da República Federativa do Brasil (BR). Brasilia (DF): Senado Federal; 1988.

6. Moraes GA. Normas regulamentadoras comentadas. $5^{\mathrm{a}}$ ed. rev. ampl. e atual. Rio de Janeiro (R)): Gerenciamento Verde/ Livraria Virtual; 2005. v.1.

7. Haber J. Amostragem. In: Wood GLB, Haber J. Pesquisa em enfermagem: métodos, avaliação crítica e utilização. Rio de Janeiro (RJ): Guanabara Koogan; 2001. da temática estudada, e 2004. Dessa forma, investigaram-se 42 resumos de publicação científica de estudos stricto sensu, observando que a grande maioria apresentou o tipo de abordagem objetiva, totalizando 38 resumos versus 4 dotados de abordagem subjetiva, sendo três dissertações e uma tese.

Assim, evidenciou-se a predominância em relação aos aspectos objetivos do tema estudado, descrevendo-se de modo incipiente os aspectos subjetivos, e foi possível conhecer e analisar à luz do referencial teórico os riscos ocupacionais retratados nos estudos e abordados de forma mais expressiva com maior ênfase ao risco biológico e, em seguida, ao químico, notando uma lacuna no que se refere aos psicossociais, físicos, ergonômicos e de acidentes. Tal lacuna deve ser preenchida, já que acreditamos que estes riscos possam favorecer ou precipitar a ocorrência de acidentes ocupacionais nos trabalhadores expostos aos mesmos.

Em face da exposição ocupacional aos diversos tipos de riscos, concordamos com Farias et al. ${ }^{14}$ ao referirem que a atitude das enfermeiras diante dos riscos e da idéia de que são inevitáveis deve se modificar, pois riscos são passíveis de prevenção. E acrescentam que "conhecê-los é fundamental para o desenvolvimento de mecanismos de controle e proteção adequados, objetivando a promoção da própria saúde e a dos demais trabalhadores"14:57.

0 estudo apresenta destaque nas áreas de ensino, pesquisa e assistência através da reflexão e construção de conhecimento, assim como a análise dos riscos que cotidianamente estão expostos os trabalhadores em seus diversos cenários laborais, atentando para sua identificação, detecção e controle.

8. Associação Brasileira de Enfermagem-ABEn. Centro de Estudos e Pesquisas em Enfermagem. Informações sobre pesquisas e pesquisadores em enfermagem. [CD-ROM]. Brasília (DF); 2001.

9. Associação Brasileira de Enfermagem. Publicações - CEPEN [online]. [citado 18 nov 2006]. Disponível em: <http:// www.abennacional.org.br>

10. Spíndola T. Prevenindo acidentes com perfurocortantes na área hospitalar. Rev Enferm UERJ 1999; 54-60.

11. Teixeira P, Valle $S$. Biossegurança: uma abordagem multidisciplinar. Rio de Janeiro (RJ): FIOCRUZ; 1996.

12. Fagundes CF. Manual de condutas: acidentes com material biológico. Profilaxia pós-exposição a sangue e outros fluidos orgânicos. Rio de Janeiro (RJ): Secretaria Municipal de Saúde; 1997.

13. Starling PBJ. Dimensões subjetivas da biossegurança nas unidades de saúde. Bol Pneumol Sanitaria 2001 jul/dez; 9(2): 58-64.

14. Farias SNP, Mauro MYC, Zeitoune RCG. Riscos no trabalho e agravos à saúde do trabalhador de enfermagem de saúde pública. Rio de Janeiro (RJ): EEAN/UFRJ; 2005. 
ANEXO

Quadro 1: Resumos identificados.

\begin{tabular}{|c|c|c|c|}
\hline 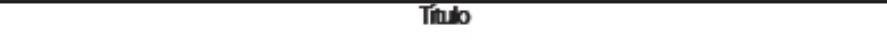 & Ano & Tpo deEsudo & Universidade \\
\hline 1. Fatores de risco numa empresa eletri citária uma perspectiva cultural & 1988 & D & UFSC \\
\hline $\begin{array}{l}2 \text { As fontes potenciais de riscos fisicos e químicos incidentes sobre os membros da equipe } \\
\text { crúrgica. }\end{array}$ & 1988 & $\mathrm{~T}$ & USP \\
\hline 3. Incêndio em centro cirúrgico. elaboraçäo de um plano hospitalar para o desastre inter no & 1989 & D & USP \\
\hline 4. Riscos $\propto$ cupacionais em hospitas: um des afio aos profissionais da área de saúde ocupacional & 1989 & D & UFSC \\
\hline $\begin{array}{l}5 \text { Contribuiçäo ao estudo sobre coletbres de live. acidentes de trabalho ocorr dos em Ribeiräo } \\
\text { Preta, estado de SP, no periodo de } 1986 \text { a } 1988\end{array}$ & 1991 & $\mathrm{~T}$ & USP \\
\hline $\begin{array}{l}6 \text { Prostituiçăa, œupaçäo de risco. aplicą̧äo de dagnóstico de enfer magem em comunidade- } \\
\text { uma proposta. }\end{array}$ & 1998 & D & UPPB \\
\hline $\begin{array}{l}\text { 7. Condiçôes e gonômicas da situą̧äo de trabalha, do pessoal de enfer magem, em uma unidade } \\
\text { de inter na̧̧â hospitala }\end{array}$ & 1995 & $\mathrm{~T}$ & USP \\
\hline $\begin{array}{l}8 \text { Tuberculose um estudo de uma situaçäo entre pacientes inter nados e equipe de entermagem } \\
\text { de um hospital escola de Riberäo Preta, Säo Paub }\end{array}$ & 1996 & D & USP \\
\hline $\begin{array}{l}\text { 9. Exposiçâa ocupacional ao vírus daAl DS e da hepatite B. anáíse da influência des crenças em } \\
\text { saúde sobre a prátca de reencapa agulhas }\end{array}$ & 1997 & D & USP \\
\hline $\begin{array}{l}10 \text { Compreendendo o signifc ado do risco de infecçäo pelo HV para trabahadores de } \\
\text { enfer magem }\end{array}$ & 1998 & D & URMG \\
\hline 11. Biossegurança: de quem é o compromisso pelo cuidado seguro & 1998 & D & UFSC-URMT \\
\hline $\begin{array}{l}12 \text { Conheciment e aplicaçäo das precauçóes universais pelos componentes da equipe de } \\
\text { enfer magem de um hospital gover namental }\end{array}$ & 1994 & D & UFSP \\
\hline 13. A cidentes ocupacionais com sangue e outros fuidos corpóreos em professionais de saúde & 1999 & D & USP \\
\hline $\begin{array}{l}14 \text { Liberdade e compromisso no agir éfco do erfer meiro dante de situaçốes de risco de } \\
\text { contaminaçáo }\end{array}$ & 1999 & D & UFP \\
\hline $\begin{array}{l}\text { 15. Riscos no trabaho e agravos à saúde do trabahador de enfermagem em Centro Municipal de } \\
\text { Saíde }\end{array}$ & 1999 & D & UFA \\
\hline 16 Entermeira em serviços de quimioter apia uma questio de saúde do trabahador & 1999 & D & UFP \\
\hline $\begin{array}{l}\text { 17. Processo de trabaho e o processo educative. construindo a prevenģăo da situagăo de risco } \\
\text { e de acidente de trabalho }(0)\end{array}$ & 1999 & D & UPC-UFPEl \\
\hline 18 Educaçä revelando os riscos @cupacionais no trabaho da enfermagem irtensiva (A) & 2000 & $\mathrm{~T}$ & UFA \\
\hline $\begin{array}{l}\text { 19. Exer cício do banho de aspersäo. um estudo sobre as prátcas, as condiçoes de trabaho ea } \\
\text { saude das trabalhadoras de enfermagem }\end{array}$ & 2000 & D & UFSP \\
\hline $\begin{array}{l}20 \text { Situaçóes de ríco para transmissäo de patógenos veiculados pelo sangue entre a equipe de } \\
\text { enfer magem de um hospital unvers tário do interior paulista }\end{array}$ & 2000 & D & USP \\
\hline 21. Risco biológco e biossegurança no cotidiano de enfermeros e auxiliaes de enfer magem & 2001 & $\mathrm{~T}$ & USP \\
\hline $\begin{array}{l}22 \text { Biossegurança no prepara, administ açäo e desca te de agentes antineoplásicos injetáves } \\
\text { pela equipe de enfermagem }\end{array}$ & 2001 & D & USP \\
\hline $\begin{array}{l}\text { 8. Distúr bos osteomusculases e o trabalho de erfer magem hospitala: estudo com auxiares de } \\
\text { enfer magem em unidade de ortopedia }\end{array}$ & 2000 & D & UERI \\
\hline 24 Estresse nos trabalhadores de enfermagem estudo em uma unidade de psiquiatria & 2000 & D & UERI \\
\hline $\begin{array}{l}25 \text { Condiḉes de trabalho e riscos par a a saide dos trabalhadores que preparam e administram } \\
\text { qumbiterápicos }\end{array}$ & 2000 & D & UERI \\
\hline 26 Segurança e os riscos do mercúro utilizado no amálgama dentà revisäo bibliográfica (A) & 2001 & D & USP \\
\hline $\begin{array}{l}\text { 27. Estudo sobre os acidentes de trabaho com exposiçä aos liquidos corporais humanos em } \\
\text { trabalhadores da saide }\end{array}$ & 2002 & D & USP \\
\hline 28 Riscos biológicos à saúde do trabalhador de entermagem em Unidade de Terapia Intensiva & 2000 & D & UFA \\
\hline $\begin{array}{l}29 \text { Exposiçäo dos trabalhadores de enfermagem às substâncias químicas: estudo em um } \\
\text { hospital público universitário }\end{array}$ & 2002 & D & USP \\
\hline $\begin{array}{l}30 \text { Perigos potenciais a que estäo expostos os trabahadores de enfermagem na manipulaçäo } \\
\text { de quimoterápicos antineoplásicos }\end{array}$ & 2002 & D & USP \\
\hline $\begin{array}{l}\text { 31. Riscos ocupacionas, acidentes do trabaho e mor bidade ertre motoristas de uma central de } \\
\text { ambulância do estado de Säo Paulo }\end{array}$ & 2002 & $\mathrm{~T}$ & USP \\
\hline 32 Riscos ocupacionas e acidentes do trabaho. uma realidade em unidade de terapia intensiva & 2002 & D & WIIAMP \\
\hline $\begin{array}{l}\text { 33. Exposiçäo ocupacional e hipersensibilidade ao látex nos trabalhadores das equipes de } \\
\text { enfer magem e médica da UTi Neonatal de um hospital universtário }\end{array}$ & 2002 & D & WIIAMP \\
\hline 34. Riscos biológicos sob a ófca de quem cuida repesentaçôes da equipe de enfer magem & 2001 & D & UNRO \\
\hline 35 Modelo exlicativo da adesäo às precauçóes-padräo. construçäo e aplicaçäa & 2003 & $\mathrm{~T}$ & USP \\
\hline $\begin{array}{l}36 \text { Estudo de acidentes de trabaho com trabahadores de enfer magem de um hospital-escola } \\
\text { do Distrito Federal }\end{array}$ & 2004 & D & UNB \\
\hline $\begin{array}{l}\text { 37. Usa, desuso ou uso nadequado dos equipamentos de poteçäo indiv dual pela equipe de } \\
\text { enfer magem na prevençäo dos riscos com material biológico }(0)\end{array}$ & 2002 & D & UFA \\
\hline 38 Mor bidade da equipe de enfermagem de um senv ço de quimioter apia & 2003 & T & UFA \\
\hline 39. Danos à saide do trabalhador de enfermagem: refexos da prática hospitalar & 2001 & D & UFA \\
\hline 40 Biossegurança conheciment, acidentes e cobertura vacinal entre enfermeiras & 2003 & D & UFSP \\
\hline $\begin{array}{l}\text { 41. A doecimento dos trabahadores de enfermagem da Fundaçäo Hospitalar do Estado de Mñas } \\
\text { Geras: refleo das mudancas no mundo do trabaho (O) }\end{array}$ & 2004 & $\mathrm{~T}$ & USP \\
\hline $\begin{array}{l}42 \text { Adesäo de trabalhadores de enfermagem ao tratamento com os antiretrovirais pós-exosição } \\
\text { ocupacional a material biológico }\end{array}$ & 2004 & D & USP \\
\hline
\end{tabular}

